\title{
Factors Predicting ObServed Cellphone USE in A MIDWESTERN USA UNIVERSITY CAMPUS AREA
}

\author{
Daniel J. Kruger, Dora Juhasz, Claire Saunders, Stephanie Misevich, Ailiya Duan, \\ Anna Heyblom, and Camille Phaneuf \\ Population Studies Center, University of Michigan, Ann Arbor, Michigan, USA
}

kruger@umich.edu

\begin{abstract}
Cellphones are an integral part of life for many adults in technologically advanced societies. There is extensive research and literature on cellphones and social technology, with most studies conducted through self-report surveys, experience sampling, and system log data. Although selfreport survey methods are useful for examining how individuals perceive and feel about cellphone related issues, self-reported cellphone usage behavior is only moderately correlated with objective system log data. Naturalistic observations complement findings from self-report survey methods and may be the best method of objectively assessing both the patterns of and influences on cellphone use in real-world social contexts. Observers documented cellphone use among individuals $(N=4079)$ in seven public areas within or immediately surrounding a large public university campus in the Midwestern USA. Observers recorded whether or not individuals were using their cellphones, as well as individual's sex, approximate age (undergraduate or older), group size, if the individual was engaged in live conversation with companions, and the prevailing weather conditions. Those engaged in live conversation were less likely to be using their cellphones than those who were not conversing with companions. Younger adults (those appearing to be in the typical undergraduate age range) were more likely to be using their cellphones than those who appeared older. Women were more likely to be using their cellphones than men. Phone use was higher in warmer weather than on colder days. Overall, this study demonstrates the value of observational studies for understanding technology use in social contexts.
\end{abstract}

Keywords: Cellphones, public use, observation, behavior 


\section{INTRODUCTION}

Cellphone use is nearly ubiquitous in industrialized countries. Currently in the USA, $77 \%$ of all adults own a smartphone, and $92 \%$ of those aged 18 to 29 own a smartphone (Pew Research Center, 2017). There are also many other adults with more basic and less expensive non-touchscreen phones. Cellphones can operate virtually anywhere, providing continuous access to one's social contacts and virtual world (Katz \& Aakhus, 2002). People report using their phones frequently, for making phone calls, sending and receiving text messages, using social media, and accessing the Internet (Rainie \& Zickuhr, 2015). Because social interactions and other uses of cellphones are constantly available, one could always be connected to their virtual social worlds and other sources of information (Bittman, Brown, \& Wajcman, 2009). The ubiquity of cellphones and their potentially continuous operation suggests that "down time" in one's connectivity has been eliminated (Bittman et al., 2009; Xie \& Newhagen, 2014).

University students consider cellphone use to be a critical aspect of their social lives (Cheever, Rosen, Carrier, \& Chavez, 2014; Chen \& Katz, 2009). Most young adults in Southern California report checking their text messages at least once an hour (Rosen, Whaling, Rab, Carrier, \& Cheever, 2013). Midwestern college students report using cellphones for nearly five hours a day (Lepp, Li, Barkley, \& Salehi-Esfahani, 2015). Cellphone use offers numerous benefits, many of them related to socialization (Campbell \& Kwak, 2011a). Cellphones can maintain connections to close others (Licoppe, 2004; Jin \& Park, 2010), provide connections to a global community (Campbell \& Kwak, 2011b), and can also help individuals navigate both mundane events and emergencies (Chapman \& Schofield, 1998). These new communication technologies are revolutionizing the ways in which people form, maintain, and even terminate social and romantic relationships (Okdie et al., 2014; Valkenburg \& Peter, 2009).

Desires to connect socially are largely responsible for the addictive properties of cell phones for undergraduates (Roberts, Yaya, \& Manolis, 2014). Those who experience greater psychological dependency on cell phones and those who are higher in attachment anxiety (worrying that partners will abandon them, etc.) are more likely to experience "phantom" phone calls or messages when none actually register on their phones (Kruger \& Djerf, 2015; Kruger \& Djerf, 2017). Undergraduates in the USA who were moderate or heavy cellphone users became increasingly anxious when they were not able to use their phones over the course of a one-hour study (Cheever et al., 2014).

People often use their cellphones in public areas (Kruger et al., 2017), even in the presence of companions (Finkel \& Kruger, 2012; Kruger et al., 2017). Although cellphones enable the remote initiation and maintenance of relationships, connecting with one's virtual social network may interfere with non-virtual socialization in immediate face-to-face contexts. Young adults consider using cellphones while conversing in person to be only moderately appropriate, and older adults view this practice even less favorably (Forgays et al., 2014). People widely agree that using cellphones in social settings interferences with live conversations (Rainie \& Zickuhr, 2015). Dividing attention between one's partner and one's phone can be detrimental to relationships (e.g., Roberts \& David, 2016). 
There is extensive research and literature on cellphones and social technology, with most studies conducted through self-report surveys, experience sampling, and system log data (Rosen, Whaling, Carrier, Cheever, \& Rokkum, 2013). Self-reported cellphone usage is only moderately correlated with objective system log data (Boase \& Ling, 2013), calling into question the accuracy of self-reported accounts of cellphone related behaviors. Naturalistic observation entails direct observation of behaviors in their natural setting, with no intervention by a researcher or confederate. The real-life context, including naturalistic variation, differentiates naturalistic observation from experimental research, where artificial environments are used to control for spurious and potentially confounding factors. In comparison to studies using self-report survey methods, naturalistic observational studies of cellphone use (e.g. Finkel \& Kruger, 2012; Kruger et al., 2017) are rare. However, naturalistic observations may be the best method of investigating cellphone use in real-world social contexts and objectively assessing the patterns of and influences on cellphone use. Observational results complement findings from self-report survey methods, which can reveal how individuals perceived and feel about cellphone related issues, a combination providing a more comprehensive understanding of the topic.

\section{Current Study:}

The current study examined the extent to which individuals on or near a large public university campus used their phones in public, and the contextual influences on cellphone use. We expected that a substantial proportion of individuals would be observed using their phones, enabling the prediction of phone use based on contextual factors. We predicted that individuals would be less likely to be observed using their phones when they were engaged in live conversations $(\mathrm{H} 1)$, due to the interference between virtual and non-virtual socialization (Forgays et al., 2014; Kruger et al., 2017; Rainie \& Zickuhr, 2015; Roberts \& David, 2016). Based on previous literature (e.g., Finkel \& Kruger, 2012; Forgays, Hyman, \& Schreiber, 2014; Kruger et al., 2017), we predicted that women would have a greater tendency to use cellphones than men (H2). Based on previous literature indicating that younger adults engage in more excessive smartphone use than older adults (e.g., Demirci et al., 2015; van Deursen et al., 2015), we predicted that undergraduate aged individuals (appearing to be 18-25 years old) would have a greater tendency to use cellphones than adults appearing older than 26 years old (H3). Observers felt that they could easily distinguish individuals who looked older than typical undergraduate age. We also predicted that individuals would be less likely to use their phones in colder weather $(\mathrm{H} 4)$, due to the trade-off between phone use and the discomfort of exposed hands at lower temperatures. We did not find previous research on rates of cell phone usage by temperature or season. 


\section{METHODS}

The research team conducted 20 observational sessions during February and March 2016 between 10:00 AM and 6:00 PM. Observers sat in unobtrusive locations in seven public areas within or immediately surrounding a large public university campus in the Midwestern USA. The campus area is highly pedestrianized, and walking is the primary mode of transportation. Observers did not interact with other individuals and reported that no one noticed them recording behaviors. Session times ranged from 30-90 minutes. Observers recorded whether or not individuals $(\mathrm{N}=4079)$ were observed using their cellphones, as well as individual's sex, approximate age (undergraduate, i.e. appeared to be 18-25 years old, or older than 26 years old), group size, if the individual was engaged in live conversation with companions, and the prevailing weather conditions. Observers were not informed of the specific predictions in the hypotheses until data collection was complete. Initial practice sessions demonstrated complete agreement between all pairs of observers, once the research team was familiar with the methodology each individual was observed once by one observer. We conducted a forward conditional binary logistic regression predicting whether or not an individual was observed using her/his phone. Potential predictors were an individual's sex, approximate age (undergraduate or older), group size, if the individual was engaged in live conversation with (a) companion(s), and ambient temperature. We conducted a post-hoc Analysis of Variance with Tukey's $b$ multiple comparison procedure to examine differences in phone use rates between lone individuals, dyads, and groups of three or more individuals.

\section{RESULTS}

There were 4079 individuals observed and coded, of these $54 \%$ were women, $46 \%$ were men, $75 \%$ were typical undergraduate age, $25 \%$ were older than typical undergraduate age, $64 \%$ were by themselves, $27 \%$ were in a pair, $9 \%$ were in a group of three or more, $35 \%$ were engaged in a live conversation, and $20 \%$ were observed using their phone. All hypotheses were supported. Live conversation status, age, ambient temperature, and sex uniquely predicted whether or not individuals were observed using their cellphones (See Table 1). Once these factors were controlled for (especially conversational status), the observed social group size (including one individual alone) did not significantly predict cellphone use. Those engaged in live conversation were less likely to be using their cellphones (5.9\%) than those who were not conversing with companions (27.9\%; See Table 2). Younger adults (those appearing to be within the typical undergraduate age range) were more likely to be using their cellphones (24.1\%) than those who appeared older $(8 \%)$. Women $(21.8 \%)$ were more likely to be using their cellphones than men (18.3\%). Phone use was higher in warmer weather than on colder days. The post-hoc comparison indicated that individuals in both dyads and groups of three or more were more likely to be using their phones than lone individuals, however there was no difference in phone use rates between dyads and larger groups. 
Table 1: Predictors of cellphone use.

\begin{tabular}{lrrrrr}
\hline & $\boldsymbol{B}$ & $\boldsymbol{S E}$ & Wald & $\boldsymbol{d f}$ & $\boldsymbol{p}$ \\
\hline (Constant) & -0.24 & 0.24 & 0.97 & 1 & .325 \\
In conversation & -1.81 & 0.12 & 224.99 & 1 & .001 \\
Age group & -1.15 & 0.12 & 86.86 & 1 & .001 \\
Temperature & 1.91 & 0.30 & 39.20 & 1 & .001 \\
Sex & -0.20 & 0.08 & 5.84 & 1 & .016 \\
\hline
\end{tabular}

Note: For Subject Sex, 1 = Female, 2 = Male; For Age group, 1 = Typical undergraduate age, $2=$ Older than tvpical underaraduate

Table 2: Proportion of individuals using phones by predictors of cellphone use.

\begin{tabular}{lll}
\hline In a conversation? & No & Yes \\
& $27.9 \%$ & $5.9 \%$ \\
Undergrade Age Subject? & Yes & No \\
& $24.1 \%$ & $8.0 \%$ \\
Temperature & Above 10C & Below 10C \\
& $23.7 \%$ & $16.2 \%$ \\
Subject Sex & Female & Male \\
& $21.8 \%$ & $18.3 \%$ \\
\hline
\end{tabular}

\section{DISCUSSION}

All hypotheses were supported. The strongest effect on cellphone use was the presence of live socialization. Those not conversing with companions were nearly five times more likely to be using cellphones compared to those who were conversing with companions. This finding provides evidence of the interference between virtual and non-virtual forms of socialization. Many adults consider using cellphones while interacting with companions inappropriate (Forgays et al., 2014), as virtual conversations interfere with live conversations (Rainie \& Zickuhr, 2015). Previous observational research indicated that individuals were more likely to use their cellphones after their social companions used their own cellphones (Finkel \& Kruger, 2012), and that individuals waiting in lines were less likely to start using their cellphones when engaged in a live conversation (Kruger et al., 2017). Also, those who are currently by themselves may see cellphones as a mechanism to connect with their social worlds (Campbell \& Kwak, 2011a; Campbell \& Kwak, 2011b; Licoppe, 2004; Jin \& Park, 2010).

The second strongest effect on cellphone use was age. Those who appeared to be in the typical undergraduate age range (18-25 years old) were three times more likely to be using their cellphones than those who appeared to be older. For current undergraduates, cell phones have always been a part of their social lives, and this age group self-reports 
high rates of cellphone use (e.g., Lepp, Li, Barkley, \& Salehi-Esfahani, 2015; Rosen, Whaling, Rab, Carrier, \& Cheever, 2013).

Individuals were $46 \%$ more likely to be using their cellphones when it was above $10 \mathrm{C}$ (50F) compared to below 10C. We interpret this as a function of discomfort from exposing bare hands on colder days. Observers noted that many individuals had their hands in their pockets on colder days. Although individuals could potentially talk with phones in their hands while wearing gloves, most gloves would impede abilities to text message and otherwise use touchscreens or keypads. Observations were well distributed across the temperature range from $-4 \mathrm{C}$ to $20 \mathrm{C}$ ( $25 \mathrm{~F}$ to $68 \mathrm{~F})$. It is possible that cellphone usage rates would be higher in temperatures above $20 \mathrm{C}$, it is probably even more likely that cellphone usage rates would be lower in temperatures below $0 \mathrm{C}$.

Although the predicted sex difference in cellphone use was confirmed, women were only $19 \%$ more likely to be observed using their phone than men, i.e., only $3.5 \%$ more of women were observed using phones compared to men. Thus, it was the weakest effect identified in the study, and likely reached statistical significance due to the large sample size. This sex difference has been identified in previous self-report survey (Forgays, Hyman, \& Schreiber, 2014) and observational studies (e.g., Finkel \& Kruger, 2012; Kruger et al., 2017). It is possible that the sex difference in cellphone use tendencies is a real, yet minor phenomenon. Women are generally thought to have greater tendencies for verbal communication compared to men (for a review, see Tannen, 1990). These observational results complement findings from self-report survey methods and may be the best method of objectively assessing both the patterns of and influences on cellphone use in real-world social contexts. Self-report surveys may elicit biased or inaccurate responding, as individuals may have inaccurate recall of events, may be affected by the demand characteristics of studies, or may exhibit socially desirable responding. Previous research has documented substantial discrepancies between self-reported cellphone use and objective data from system logs (Boase \& Ling, 2013). Self-report survey methods may be useful for examining attitudes towards issues related to cell phone use, however policy decisions should be informed by naturalistic observations of actual behavior.

\section{Limitations}

We assessed phone use in the campus area of a university in the Midwestern USA. Most subjects appeared to be of typical undergraduate age, i.e., 18-25 years old. Social norms regarding public cell phone use may vary across cultural contexts, for example nonstudent populations and settings where cell phone usage is relatively more expensive and/or paid according to minutes of use. Although overall rates of cellphone use may vary, we expect that the pattern of effects will generally replicate across contexts.

\section{Conclusion}

Our results advance the understanding of cellphone use behaviors, identifying several factors predicting cellphone use. We document evidence of the interference between virtual and non-virtual forms of socialization. Naturalistic observations complement findings from self-report survey methods, which may exhibit response biases, and objective system log data, which does not record contextual factors. Overall, this study 
demonstrates the value of observational studies for understanding technology use in social contexts.

\section{ACKNOWLEDGEMENT}

We thank the University of Michigan's Undergraduate Research Opportunities Program for support of this project.

\section{REFERENCES}

Bittman, M., Brown, J. E., \& Wajcman, J. (2009). The cellphone, constant connection and time scarcity in Australia. Social Indicators Research, 93(1), 229-233. DOI

Boase, J., \& Ling, R. (2013). Measuring mobile phone use: Self-report versus log data. Journal of Computer-Mediated Communication, 18(4), 508-519. DOI

Campbell, S. W., \& Kwak, N. (2011a). Mobile communication and civil society: Linking patterns and places of use to engagement with others in public. Human Communication Research, 37(2), 207-222. DOI

Campbell, S. W., \& Kwak, N. (2011b). Political involvement in 'mobilized' society: The interactive relationships among mobile communication, network characteristics, and political participation. Journal of Communication, 61, 1005-1024. DOI: 10.1111/j.14602466.2011.01601.x

Chapman S., \& Schofield, W. N. (1998). Lifesavers and Samaritans: Emergency use of cellular (mobile) phones in Australia. Accident Analysis and Prevention, 30(6), 815-819. DOI

Cheever, N. A., Rosen, L. D., Carrier, L. M., \& Chavez, A. (2014). Out of sight is not out of mind: The impact of restricting wireless mobile device use on anxiety levels among low, moderate and high users. Computers in Human Behavior, 37, 290-297. DOI

Chen, Y-F. \& Katz, J.E. (2009). Extending family to school life: College students' use of the mobile phone. International Journal of Human-Computer Studies, 67(2), 179-191. DOI

Demirci, K., Akgonul, M., \& Akpinar, A. (2015). Relationship of smartphone use severity with sleep quality, depression, and anxiety in university students. Journal of Behavioral Addictions, 4(2), 85-92. DOI

Finkel, J.A. \& Kruger, D.J. (2012). Is cellphone use socially contagious? Human Ethology Bulletin, 27, $15-17$.

Forgays, D. K., Hyman, I., \& Schreiber, J. (2014). Texting everywhere for everything: Gender and age differences in cellphone etiquette and use. Computers in Human Behavior, 31, 314-321. DOI

Jin, B., \& Park, N. (2010). In-person contact begets calling and texting: Interpersonal motives for cellphone use, face-to-face interaction, and loneliness. Cyberpsychology, Behavior, and Social Networking, 13, 611-618. DOI

Katz, J., \& Aakhus, M. (2002). Perpetual contact: Mobile communication, private talk, public performance. Cambridge: Cambridge University Press. DOI 
Kruger, D.J., \& Djerf, J.M. (2015). High ringxiety: Attachment anxiety predicts experiences of phantom cell phone ringing. Cyberpsychology, Behavior, and Social Networking, 19(1), 1-4. DOI

Kruger, D.J., \& Djerf, J.M. (2017). Bad vibrations? Cell phone dependency predicts phantom communication experiences. Computers in Human Behavior, 70, 360-364. DOI

Kruger, D.J., Duan, A., Juhasz, D., Phaneuf, C.V., Sreenivasa, V., Saunders, C., Heyblom, A., Sonnega, P., Day, M.M., \& Misevich, S.L. (2017). Cellphone use latency in a university area population in the Midwestern USA. Journal of Technology in Behavioral Science, 2(1), 56-59. DOI

Lepp, A., Li, J., Barkley, J., \& Salehi-Esfahani, S. (2015). Exploring the relationships between college students' cellphone use, personality and leisure. Computers in Human Behavior, 43, 210-219. DOI

Licoppe, C. (2004). 'Connected' presence: The emergence of a new repertoire for managing social relationships in a changing communication technoscape. Environment and Planning D: Society and Space, 22(1), 135-156. DOI

Okdie, B. M., Ewoldsen, D. R., Muscanell, N. L., Guadagno, R. E., Eno, C. A., Velez, J. A., \& ... Smith, L. R. (2014). Missed programs (you can't TiVo this one): Why psychologists should study media. Perspectives on Psychological Science, 9(2), 180-195. DOI

Pew Research Center. (2017). 10 facts about smartphones as the iPhone turns 10. Retrieved from http://www.pewresearch.org/fact-tank/2017/06/28/10-facts-aboutsmartphones/

Rainie, \& Zickuhr (2015). Americans views on mobile etiquette. Pew Research Center. Retrieved from http://www.pewinternet.org/2015/08/26/americans-views-onmobile-etiquette/

Roberts, J. A., \& David, M. E. (2016). My life has become a major distraction from my cellphone: Partner phubbing and relationship satisfaction among romantic partners. Computers in Human Behavior, 541, 34-141. DOI

Rosen, L.D., Whaling, K., Carrier, L.M., Cheever, N.A., and Rokkum, J. (2013). The Media and Technology Usage and Attitudes Scale: An empirical investigation. Computers in Human Behavior, 29(6), 2501-2511. DOI

Rosen, L. D., Whaling, K., Rab, S. A., Carrier, L. M., \& Cheever, N. A. (2013). Is Facebook creating "iDisorders"? The link between clinical symptoms of psychiatric disorders and technology use, attitudes and anxiety. Computers in Human Behavior, 29(3), 1243-1254. DOI

Tannen, D. (1990). You just don't understand: Women and men in conversation. New York: Ballantine.

Valkenburg, P.M., \& Peter, J. (2009). Social consequences of the Internet for adolescents: A decade of research. Current Directions in Psychological Science, 18(1), 1-5. DOI

van Deursen, A. J. A. M., Bolle, C. L., Hegner, S. M., \& Kommers, P. A. M. (2015). Modeling habitual and addictive smartphone behavior: Modeling habitual and addictive smartphone behavior: The role of smartphone usage types, emotional intelligence, social stress, self-regulation, age, and gender. Computers in Human Behavior, 45, 411-420. $\underline{\mathrm{DOI}}$

Xie, W., \& Newhagen, J. E. (2014). The effects of communication interface proximity on user anxiety for crime alerts received on desktop, laptop, and hand-held devices. Communication Research, 41(3), 375-403. DOI 